\title{
ESCOLA PÚBLICA DE TEMPO INTEGRAL NO BRASIL: FILANTROPIA OU POLÍTICA DE ESTADO?
}

\author{
Ana Maria Cavaliere*
}

\begin{abstract}
RESUMO: A necessidade da escola de tempo integral no Brasil tornou-se uma unanimidade, mas, seu sentido ainda não está suficientemente estabelecido. Vista como um direito de todos, estratégico para a cidadania, é tarefa de grande porte político e financeiro e requer tratamento de política de Estado assumida cooperativamente por todos os entes da federação. Vista como dispositivo compensatório, dirigido a alguns alunos, tende a assumir caráter provisório, instável, com base em trabalho voluntário ou em parcerias com organizaçóes sociais de variados matizes. Este artigo analisa os elementos que compóem o atual debate sobre o tema.
\end{abstract}

Palavras-chave: Escola de tempo integral. Educação integral. Filantropia.

\section{FULL-TIME PUBLIC EDUCATION IN BRASIL: PHILANTHROPY OR STATE POLICY?}

ABSTRACT: The need for full-time public education in Brazil has reached unanimity, even though its meaning has not yet been fully established. Conceived as a universal right, and also as strategic for citizenship, it is a tremendous political and financial task, which requires that a State policy approach be cooperatively undertaken by all federate entities. Seen as a compensatory device, merely directed towards some students, it tends to assume a provisionary and unstable character, based either on voluntary work or on partnerships among different types of social organizations. This paper analyzes the elements which compose the current debate about the theme.

Keywords: Rural Full-time education. Integral Education. Philanthropy.

\section{ECOLE PUBLIQUE À TEMPS PLEIN AU BRÉSIL: PHILANTHROPIE OU POLITIQUE D'ÉTAT?}

RÉSUMÉ: La nécessité de l'école à temps plein au Brésil s'est devenue une unanimité, mais son sens n'est pas encore assez établi. C'est une mission politique et financière à grande échelle, vue comme un droit stratégique pour la citoyenneté. Elle requiert un traitement de politique d'État assumée en

* Universidade Federal do Rio de Janeiro, Faculdade de Educação, Programa de Pós-Graduação em Educação, Rio de Janeiro, RJ, Brasil. E-mail de contato: anacavaliere@uol.com.br 
coopération par toutes les entités de la fédération. Vue comme un dispositif compensatoire s'adressant à quelques élèves, assume un caractère provisoire et instable, sur la base du bénévolat ou en partenariat avec des organisations sociales de différentes natures. Cet article analyse les éléments composés par l'actuel débat sur ce thème.

Mots-clés: École à temps plein. Éducation intégrale. Philanthropie.

\section{Os elementos do problema}

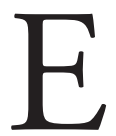

ste texto inicia-se com uma indagação que orientará o seu desenvolvimento: a escola de tempo integral no Brasil promove o cumprimento do direito à educação? Tal como na maioria das perguntas sobre questóes educacionais, a resposta não pode ser dada - como gostariam os repórteres do cotidiano - em termos de sim ou não. O direito à educação traduz-se hoje, no Brasil, como o direito a um padrão de qualidade educacional, em que pesem as dificuldades em estabelecer-se um consenso sobre a própria noção de qualidade, mesmo quando se afirma a ideia de uma qualidade "socialmente referida". Ainda que pouco precisa, a expectativa pela qualidade educacional está, mais do que nunca, presente na sociedade brasileira que não apenas percebe a diferença qualitativa entre as escolas existentes - diferença rigorosamente espelhada na hierarquia social - mas também se pergunta sobre o que a escola pode e deve ensinar e quais as suas responsabilidades específicas. É em função dessa expectativa que a escola de tempo integral aparece como elemento para um possível avanço em direção à referida qualidade, a depender do sentido e das funçóes que a ela se venha atribuir.

Ao contrário de outras medidas recentes, como a ampliação do período da obrigatoriedade escolar, a ampliação da jornada suscita dúvidas e questionamentos. Do ponto de vista do direito, qual seria a diferença entre essas duas medidas? Pode-se apontar que a primeira delas é direcionada inequivocamente a todos os cidadáos, sendo consequência do consenso de que o "ponto de corte" do mínimo necessário em anos de escolarização foi modificado. A educação escolar dos 4 aos 17 anos tornou-se direito e obrigação do Estado e da sociedade. Já a segunda medida, a despeito de todo um arcabouço legal que vem sendo construído para seu suporte, ainda permanece dúbia quanto ao fato de ser ou não um direito de todos, e, no limite, de vir a ser ou não obrigatória. Seria uma necessidade imperiosa e geral do conjunto da sociedade brasileira ou uma medida compensatória, emergencial, para os mais desprovidos economicamente? Seria uma medida opcional a depender de realidades regionais ou locais específicas, ou seria uma medida necessária apenas para as crianças menores, dependentes de cuidados e proteção durante o dia inteiro? São esses aspectos, ainda pouco amadurecidos, que têm impedido uma inequívoca resposta sim, à pergunta formulada no início deste 
texto. Acresça-se ainda o fato de que a tradição escolar brasileira, mesmo para as elites, é de escola de turno parcial, só recentemente tendo aumentado a oferta, nas escolas privadas, do horário integral.

Uma das maneiras de se encarar a questão, que a afasta da condição de direito universal, é a compreensão da escola de tempo integral como um dispositivo válido para alguns alunos e não para outros, que é reforçada pela oferta seletiva do regime no interior das escolas. Nesse caso, ela se configura como educaçáo compensatória, focada nos mais necessitados a fim de, por meio da intensificação da ação escolar, fazer valer a igualdade de oportunidades educacionais.

A segunda maneira de encarar a questão, que a aproxima da condição de direito universal, se baseia na hipótese de que, sobre a duração da jornada escolar, houve também uma evolução no consenso social. O seu aumento estaria relacionado à consideração de que, na vida contemporânea, em todos os grupos sociais, e para grande parte das realidades regionais e faixas etárias, houve mudança de patamar da expectativa quanto à carga de responsabilidade educacional da escola, que teria se ampliado significativamente. Além da instrução escolar, ela estaria implicada na educação física e moral, na educação para a cidadania, na educação para a sociedade da informação e da comunicação, na difusão cultural, na socialização primária no caso das crianças pequenas e, no caso dos jovens, na formação para o trabalho. Tudo isso seria parte da justificativa para a ampliação da jornada e conformaria o que vem sendo chamado de "educação integral".

É evidente que assumir a segunda maneira de encarar a questão não excluiria a possibilidade de que, em determinados casos, as escolas de tempo integral favoreceriam a diminuição dos efeitos da desigualdade social sobre a desigualdade educacional, ainda que náo se constituíssem como um dispositivo específico para tal.

Essas ponderações exigem uma resposta mais qualificada à questão. Analisaremos os marcos legais que hoje envolvem a ampliação da jornada escolar no Brasil; as expectativas da sociedade por uma escola de tempo integral e o conceito de educação integral que tem sido a ela associado; os registros oficiais do crescimento das matrículas nesse regime; o formato de ampliação da jornada hoje predominante, baseado no programa governamental Mais Educação, buscando extrair desse conjunto os significados e tendências conceituais e organizacionais que se expandem, com suas repercussóes político-pedagógicas para, finalmente, retornar à questão inicialmente formulada.

\section{Evolução da regulamentação}

É notório que a regulamentação sobre a escola de tempo integral tem caminhado para o seu estabelecimento como direito universal. Se inicialmente, na 
Lei de Diretrizes e Bases da Educação Nacional - LDB/1996, esse tipo de escola era destinado exclusivamente ao ensino fundamental, a regulamentação posterior foi ampliando seu escopo.

A LDB afirma em seus Artigos 34 e 87 que a ampliação da jornada escolar será feita "progressivamente", "a critério dos sistemas de ensino", para o "ensino fundamental", nas "redes escolares urbanas". Observa-se que a proposição nasce com uma margem grande para interpretaçóes e omissóes. Documentos posteriores a vêm refinando, embora sua condição em termos político-legais não esteja ainda estabilizada. No cerne da legislação concernente, a lei do Fundeb (BRASIL/ MEC, 2007) é das mais importantes pois especifica aportes financeiros maiores para as matrículas em tempo integral, diferenciando os acréscimos de acordo com os níveis de ensino: creche-10\%; pré-escola-15\%; educação fundamental-25\% e ensino médio-30\%. Assim, foi a lei do Fundeb que primeiro "levou" a escola de tempo integral para toda a educação básica.

Além da LDB e do Fundeb, os dois Planos Nacionais de Educação, estabelecidos para os períodos 2001-2011 (BRASIL, 2001) e 2014-2024 (BRASIL, 2014) e o Plano de Metas Compromisso Todos pela Educação (PDE 2007) (BRASIL, 2007a), trazem diretrizes relacionadas a Escola de Tempo Integral (ETI). Mesmo cientes das diferentes naturezas e funçóes desses documentos para o planejamento e regulação da educação, os tomamos aqui como expressóes aproximadas do pensamento vigente na sociedade sobre o assunto em suas respectivas épocas.

Os dois Planos Nacionais de Educação e o PDE trazem algumas diferenças entre si, no que se refere às ETI, a serem notadas pois que indicam sentidos.

No Plano aprovado em 2001 (PNE 2001) ficou estabelecida a "prioridade de tempo integral para as crianças das camadas sociais mais necessitadas", "para as crianças de idades menores", para as "famílias de renda mais baixa, quando os pais trabalham fora de casa”. (BRASIL, 2001) Nele a ETI não aparece como um item específico, isto é, como uma meta em si mesma. Ela aparece diluída nos itens do Plano que se organizam pelos níveis e modalidades de ensino. Ela está presente na educação infantil e no ensino fundamental, mas não no ensino médio.

Nas Diretrizes da educação infantil, o foco da ETI nos "mais necessitados" e nas "idades menores" é acompanhado da seguinte advertência:

Essa prioridade não pode, em hipótese alguma, caracterizar a educação infantil pública como uma ação pobre para pobres. $\mathrm{O}$ que este plano recomenda é uma educaçáo de qualidade prioritariamente para as crianças mais sujeitas à exclusão ou vítimas dela. A expansão que se verifica no atendimento das crianças de 6 e 5 anos de idade, conduzirá invariavelmente à universalização, transcendendo a questão da renda familiar. (BRASIL, 2001) 
Já nas Diretrizes do ensino fundamental, afirma o plano:

$\mathrm{O}$ atendimento em tempo integral, oportunizando orientação no cumprimento dos deveres escolares, prática de esportes, desenvolvimento de atividades artísticas e alimentação adequada, no mínimo em duas refeiçôes, é um avanço significativo para diminuir as desigualdades sociais e ampliar democraticamente as oportunidades de aprendizagem. (BRASIL, 2001)

Apesar das ressalvas, é acentuado no PNE-2001 o sentido compensatório atribuído à escola de tempo integral.

Seguindo para o texto do PNE aprovado em 2014 / PNE-2014, sua análise mostra que a questâo se tornou mais importante no debate educacional. O sentido compensatório continua presente, especialmente pela priorização dos setores mais vulneráveis da população. Entretanto, nele a ETI é uma meta específica - meta 6 (composta por 9 itens) - para todos os níveis da educação básica, no mesmo patamar de metas como a universalizaçáo do ensino fundamental ou a garantia de planos de carreira para todos os profissionais docentes. Ou seja, há uma evidente mudança de estatura do tema na linha que vai da LDB ao PNE-2014.

Há nele a previsão de oferta, até 2024, de educação em tempo integral em, no mínimo, $50 \%$ das escolas públicas de forma a atender pelo menos $25 \%$ de todos os alunos. Mantém-se a ênfase da educação infantil como destinatária do tempo integral e também, no item 6.2, a prioridade para os setores vulneráveis da população:

Instituir em regime de colaboração, programa de construção de escolas com padrão arquitetônico e de mobiliário adequado ao atendimento em tempo integral, prioritariamente em comunidades pobres ou com crianças em situaçáo de vulnerabilidade social. (BRASIL, 2014)

Ressalte-se no trecho acima a menção à construção de escolas, ausente no PNE-2001, representando um avanço à implantação consequente das ETI. Outro aspecto relevante, presente nos dois Planos, trata da implementaçáo gradual da jornada integral para os docentes de ETI.

Para a execução das atividades nas ETI, uma novidade surge no PNE2014: a possibilidade de parcerias com entidades da sociedade civil é fortalecida pela citação da Lei 12.101 (BRASIL, 2009) que regulamenta a atuaçấo de entidades beneficentes de assistência social e abre caminhos, no item 6.6, para a participação de organizaçôes sociais de variados matizes na oferta de atividades complementares ao horário escolar convencional. Relacionando-se esse item ao 
conteúdo do item 6.1, que afirma a oferta de educação pública básica em tempo integral "na escola ou sob sua responsabilidade" (grifo nosso), temos o esboço de um desenho que fundamenta uma concepçáo particular de ETI, em franca expansão.

Esses dois itens da meta 6 revelam que, entre a elaboração dos dois planos, de 2001 a 2014, consolidou-se a concepção de ETI que se estrutura por meio de atividades complementares ao turno regular, que podem ser oferecidas por outras instâncias que não a escola - em tese sob a coordenação desta - dentro ou fora das suas dependências e por agentes voluntários, para além dos professores, o que traz mudanças significativas à concepção até então vigente de ETI.

Também corroborou o predomínio dessa concepção o lançamento do PDE em 2007, cuja simbiose com iniciativa de mesmo nome elaborada anteriormente por organizaçóes de origem empresarial recebeu diversas críticas (SAVIANI, 2007), mas trouxe de positivo uma mudança de patamar da implicação do governo federal nas questóes da educação básica nacional.

Esse plano de metas, estruturado em programas, apresenta, entre outros, o Programa Mais Educação (PME), que financia e orienta a ampliação da jornada escolar em escolas de todo o país. Está presente no Mais Educaçâo a ideia, que preside o PDE, de mobilização da sociedade para a melhoria da qualidade da educação. A introdução ao Plano reforça a característica da escola de espaço comunitário que deve firmar parcerias externas visando a melhoria da infraestrutura e dos projetos socioculturais, em sintonia com os demais espaços e equipamentos públicos ou privados das cidades.

Alguns itens que introduzem as metas do PDE são particularmente importantes para as ETI. No Art. 2o, item IV, surge a palavra "contra-turno", e no item VII aparece pela primeira vez a formulação "educandos sob responsabilidade da escola para além da jornada escolar" que será mais tarde reiterada, como já visto, no PNE 2014. Quanto às parcerias o Art. 7o afirma que:

Podem colaborar com o Compromisso, em caráter voluntário, outros entes, públicos e privados, tais como organizaçóes sindicais e da sociedade civil, fundaçóes, entidades de classe empresariais, igrejas e entidades confessionais, famílias, pessoas físicas e jurídicas que se mobilizem para a melhoria da qualidade da educação básica. (BRASIL, 2007a)

Os aspectos acima listados estão no cerne das questôes que hoje compóem o debate sobre as ETI. As emergências colocadas pela realidade social associadas às dificuldades em criar em grande escala ou transformar escolas convencionais em ETI, ajudaram a dirigir as propostas do PME para um tipo de solução que se encontra na encruzilhada entre uma saída que pode contribuir efetivamente com 
a melhoria da qualidade educacional e outra que reforça os estigmas da escola pública precária e de fraca ambição.

Em síntese, as premissas para a compreensão dessa solução em curso, contidas na regulamentação aqui analisada, são as seguintes: atividades complementares, contra-turno, aluno sob a responsabilidade da escola (mas não necessariamente na escola) e, como corolário o conceito de educaçáo integral, que abordaremos mais adiante. Estará o modelo, baseado nessas premissas, que ganha força em todo o território nacional, caminhando na direção das expectativas da sociedade brasileira?

\section{Expectativa social}

Foi notória a presença da "bandeira" das escolas de tempo integral na campanha eleitoral de 2014 tanto para os cargos do Poder Legislativo como do Poder Executivo e em todos os partidos. Imaginando-se que, em geral, os candidatos estão sintonizados com as expectativas da população, o momento político reafirmou uma demanda social.

Não parece haver dúvida de que uma das grandes motivaçóes para a ampliação da jornada escolar é a necessidade das famílias de terem as crianças e adolescentes protegidos e assistidos durante o período de trabalho dos pais. Essa é uma questão candente hoje em diversos países ocidentais que, mesmo quando possuem jornadas escolares longas, dificilmente elas são compatíveis com a carga horária de trabalho dos adultos - pais e mães (PEREYRA, 2014), tudo agravado pelas condiçôes objetivas da vida cotidiana nas metrópoles. Mas a explicação para o crescimento da demanda não se esgota nisso. Muitos imaginam que mais tempo diário de escola trará resultados escolares melhores, embora ainda não existam pesquisas conclusivas no Brasil que os relacionem. Na literatura internacional sobre eficácia escolar, o tempo, ou a falta dele - necessariamente acompanhado das formas de sua utilização - é uma das variáveis importantes (COMPÈRE, 1997; BROOKE; SOARES, 2008) na explicação dos bons e maus resultados.

No Brasil de 2014, a forte presença da temática pode refletir, além das necessidades advindas da generalização do trabalho feminino, o aumento da mobilidade social, com o crescimento da chamada "nova classe média" e o decorrente aumento da expectativa dessa parte da população em relaçáo à escola. Esse comportamento, já identificado por importantes autores da Sociologia da Educação, é típico das fraçôes de classe em ascensão que investem e acreditam na possibilidade da educação escolar consolidar sua mudança de extrato social (BOURDIEU, 1998), diferentemente das classes fortemente escolarizadas que 
investem em sua capacidade de escolha autônoma de atividades extraescolares, de acordo com seus perfis culturais e econômicos.

O entendimento de que a população brasileira espera mais da escola e, para além da proteção e cuidados com crianças e adolescentes, busca aquilo que nela é sua função típica, conduz a que se encare a solução político-organizacional da ETI, que vem se generalizando no país, com apreensão. A ampliação da jornada escolar pela anexação de um turno adicional ou um "contra-turno", entendido como "complementar", fundamentalmente distinto do tempo regular e destinado a apenas alguns alunos, pode ser um passo em falso na busca da melhoria da qualidade da educação brasileira. Vejamos o porquê.

O Programa Mais Educação atua provendo recursos às escolas, por meio do Programa Dinheiro Direto na Escola (PDDE), para que adquiram materiais didáticos, realizem adaptação e manutenção prediais e remunerem, pela Lei do Voluntariado (BRASIL, 1998), os agentes educacionais que desenvolvem as atividades. As escolas aderem ao programa, mas há critérios de prioridade baseados em concentração populacional, vulnerabilidade social e baixo Ideb. (BRASIL, 2007b) Cada escola, por sua vez, seleciona o grupo de alunos participantes e escolhe os macrocampos temáticos. ${ }^{1} \mathrm{Em}$ materiais de apoio ao programa ${ }^{2}$ incentiva-se que as atividades sejam realizadas em espaços externos à escola, com base nos princípios das cidades educadoras (CABEZUDO, 2004). Em alguns casos os responsáveis por esses espaços recebem apoio financeiro para a sua manutenção.

Com esse formato, a desconexão entre as atividades do PME e as atividades ordinárias da escola foi cedo percebida. A transferência do programa na estrutura do Ministério da Educação, da Secretaria de Educação Continuada, Alfabetização, Diversidade e Inclusão (Secadi), onde se originou, para a Secretaria da Educação Básica (SEB), em 2011, pode ter sido uma tentativa de minimizar essa desconexão, além de indicar o aumento do porte do programa no país.

Uma ampliação da jornada pouco ou nada amarrada ao projeto pedagógico da escola ou ancorada na ideia da complementação, ou da mera ocupação do tempo, é insuficiente frente ao desafio educacional que o Brasil tem pela frente e não corresponde à expectativa da população, que, em situaçôes já relatadas (SILVA, 2013) passa a desvalorizá-la.

Essa solução organizacional do tempo integral, que na verdade não constrói uma escola de tempo integral e nem cria as condiçóes para o desenvolvimento da chamada "educação integral", mas apenas oferece um regime escolar diferenciado para os alunos "mais necessitados", gera uma excessiva dispersão de objetivos, ao mesmo tempo em que não mexe com o "coração" da instituição e pode levar a um trabalho com identidade educacional inespecífica, ao sabor de idiossincrasias locais e pessoais, ainda que em alguns casos ele possa aliviar tensóes 
e situaçôes emergenciais relacionadas aos direitos humanos específicos da infância e da adolescência.

As escolas são instituiçóes complexas e uma ETI é ainda mais complexa. Primeiramente, não temos construçóes escolares preparadas para a rotina em tempo integral e todas estão ocupadas por, no mínimo, dois grupos de alunos por dia. Construir e reformar escolas é condição sine qua non a um projeto de médio e longo prazo para a implantação das ETI. Em segundo lugar, não há conceito ou prática firmados sobre o que seja educação integral escolar. Outra condição, portanto, é formular/aperfeiçoar modelos de trabalho articulando áreas disciplinares e temáticas, o que necessariamente terá que ser feito no âmbito das discussóes mais aprofundadas sobre currículo. Uma outra condição ainda é aumentar o efetivo de professores e incorporar, regularmente e náo precariamente, profissionais de diferentes formaçóes, para além dos professores.

Se o parágrafo anterior pode ser lido como extravagante frente às reais condiçóes de financiamento e organização da educação pública, sem as preocupaçôes que ele traz, as iniciativas hoje em curso de ampliaçáo da jornada escolar podem desvirtuar caminhos e naturalizar a precariedade do trabalho educacional, justamente quando se pretende fortalecê-lo.

\section{"Educação integral" entre transformação e slogan}

O Programa Mais Educação trouxe à baila, com força de bandeira política e não apenas de categoria acadêmica, a expressão "educação integral". Essa última, que é apresentada e debatida em textos de apoio pedagógico ao PME, também começa a aparecer em substituição à expressáo "escola de tempo integral" inclusive em documentos do FNDE e do Censo Escolar.

Cabe então perguntar o que esse conceito expressa e agrega, no momento, à realidade educacional brasileira?

O que vem sendo chamado de educação integral é um grande conjunto de atividades de diferentes naturezas, às quais se junta o reforço escolar. Ela é o carro chefe do PME, mas náo só dele. Há programas como o Segundo Tempo do Ministério dos Esportes, e no MEC o Escola Aberta e o Programa Ensino Médio Inovador (ProEMI), que vêm sendo tratados em conjunto com o PME na estruturação da chamada educação integral.

Em 2014, Resolução do FNDE (BRASIL, MEC/FNDE, 2014), utilizando fartamente a expressão educação integral vincula o PME ao Programa Escola Aberta e atualiza a regulamentaçáo do repasse de verbas para as escolas por meio do PDDE, para que "[...] realizem atividades de educação integral e funcionem nos finais de semana, em conformidade com o Programa Mais Educação" (grifo 
nosso). A Resolução se destina a apoiar atividades variadas visando a ampliação do tempo de permanência na escola, a melhoria da qualidade do trabalho educativo, focalizando as comunidades mais vulneráveis e minoritárias ou excluídas socioculturalmente. Ela parte do entendimento de que "[...] a escola é um espaço no qual a vivência democrática pode ser exercitada por meio de atividades educativas, lúdicas e recreativas".

No PME a educação integral expressa a superação de uma visão que limita a tarefa escolar às disciplinas convencionais, mas expressa também uma metodologia organizacional, um modo de fazer essa ampliação das funçóes da escola. Esse modo consiste na justaposição à rotina escolar de atividades complementares, chamadas de "atividades de educação integral". Por isso, além de um conteúdo político-curricular, a expressão educação integral adquiriu também um conteúdo político-organizacional. Referir-se a "atividades de educação integral" é considerar que há atividades especializadas que, em si mesmas, promovem educação integral. Parece que toma-se a "nuvem por Juno". Se levarmos em consideração os múltiplos sentidos históricos e filosóficos do termo educação integral (CAVALIERE, 2009), nenhuma atividade pode carregar em si esse atributo. O eufemismo embute a tentativa de manter as atividades conectadas ao projeto da escola, porém, na prática, o modelo organizacional é desfavorável, mesmo quando as atividades acontecem no interior da escola. Pesquisas de campo recentes já observaram esse fenômeno. (SOUZA, 2012; MOTA, 2013)

Dada a multiplicidade de significados atribuíveis à expressão educação integral, é necessário fixar alguns de seus elementos intrínsecos: ela trata o indivíduo como um ser complexo e indivisível; no âmbito escolar se expressa por meio de um currículo, também integrado, e que não é dependente do tempo integral, embora possa se realizar melhor com ele; se empenha na formação integral do indivíduo em seus aspectos cognitivos, culturais, éticos, estéticos e políticos. E, acrescentaríamos, somente é defensável, em uma versão escolarizada, se tiver como prática e horizonte um radical sentido público e democrático. Esse horizonte é que a impediria de invadir certos terrenos da vida privada, como, por exemplo, a religiosidade. Quando a escola se propõe a ultrapassar a mera instrução escolar, ela se encontra frente à sensível fronteira entre as esferas da vida pública e da vida privada dos indivíduos - alunos e professores. Essa fronteira nem sempre está claramente dada. Se isso não impede que a instituição escolar venha a atender a expectativa da população de ser educacionalmente mais abrangente, recomenda cautela na formulação de um currículo correspondente, de interesse universal.

Apesar da utilização do termo como epíteto ou mesmo slogan, o tipo de trabalho que vem sendo realizado nas escolas, a partir do PME, na maioria das vezes passa longe de uma prática que poderia vir a ser nominada de educação integral, visto que o modelo organizacional é liminarmente incompatível com a sua realização. 


\section{O tempo integral no Censo Escolar}

Os números mais recentes do Censo Escolar relacionados à ETI mostram que entre 2010 e 2013, a soma das matrículas em tempo integral do ensino fundamental e médio passou de 1.327.129 para 3.549.300. Um crescimento de mais de 160\%. (BRASIL, MEC/INEP, 2013)

Uma primeira observação a ser feita sobre os números da ampliação da jornada escolar refere-se à forma como o Censo Escolar passou a tratar o tema a partir de 2010, sendo o primeiro a incluir a informação sobre matrículas em tempo integral no ensino fundamental. Até entâo a única referência no Censo à duração da jornada se referia à quantidade de turmas com turnos de "menos de 4 horas, 4 horas, entre 4 e 5 horas e com mais de 5 horas", informação que permanece, nesse mesmo formato, até o Censo de 2013.

Na Sinopse Estatística do Censo de 2010 (BRASIL, MEC/INEP, 2010), em seguida à então nova tabela "Matrículas em tempo integral no ensino fundamental" aparece outra denominada "Matrículas em turmas de atividades complementares no ensino fundamental". Essas duas novas tabelas se repetem em 2011, 2012 e 2013 (BRASIL, MEC/INEP, 2011, 2012, 2013) e, a partir de 2011 o registro passa a ser feito também para o ensino médio. Nas tabelas das turmas de atividades complementares, são listados itens, disciplinares ou não, tais como matemática; letramento; futebol e futsal; brincadeiras, jogos não estruturados. recreaçãollazer, festas; bandalfanfarra; capoeira e outros.

Os resumos técnicos dos Censos Escolares relativos a 2011 e 2012 (BRASIL. MEC/INEP, 2012, 2013) se referem à "oferta de educação em tempo integral e atendimento complementar".

Observa-se que nas Sinopses Estatísticas anuais são apresentadas as matrículas em tempo integral mas não as turmas. $\mathrm{O}$ registro das turmas em tempo integral perdeu o sentido visto que os alunos selecionados são reorganizados em novos grupos de atividades. Destaque-se também a divulgação, associada ao levantamento das matrículas em tempo integral, das "matrículas em turmas de atividades complementares", ou seja os novos grupos de atividades, o que confirma a prevalência do modelo organizacional típico do PME.

A destacar ainda o fato de que uma "apresentação coletiva" prévia do resumo técnico do Censo Escolar de 2013, publicada em fevereiro de 2014 pelo MEC (Brasil. MEC/INEP, 2014), usa pela primeira vez o termo "educação integral" em referência às informaçôes sobre "matrículas em tempo integral e atividades complementares". Assim, o registro estatístico da ampliação da jornada escolar acompanha a proposta do Mais Educação, que não organiza unidades escolares 
em tempo integral e nem turmas em tempo integral, mas alunos selecionados, rearrumados em grupos que participam de "atividades de educação integral".

Quanto ao cumprimento das sete horas necessárias para a configuração regulamentar do tempo integral, a explicação a seguir, presente no resumo técnico do Censo Escolar de 2012, revela fragilidades no modelo: "Dentre as matrículas de educação em tempo integral, $78 \%$ possuem tempo de escolarização menor que 7 horas; porém, quando somado o tempo em atividade complementar, cumprem a duraçẫo exigida pelo Fundeb.”

A situação atual, identificada pelo Sistema Integrado de Monitoramento e Controle do MEC (BRASIL/MEC, 2014), com base no Censo Escolar de 2013, mostra que, no Brasil, considerados todos os níveis de ensino, inclusive a educaçáo infantil, o percentual de "escolas com alunos que permanecem pelo menos 7 horas em atividades escolares" é de 34,7\% e de "alunos que permanecem pelo menos 7 horas em atividades escolares" é de 13,4\%. Regionalmente, temos que, em 2013, o Centro-Oeste apresenta o maior índice nacional de escolas com alunos em tempo integral, $49,5 \%$, sendo de $13,0 \%$ a proporçấo de alunos em tempo integral na região. $\mathrm{Na}$ região Sul, observa-se o maior índice nacional de alunos em tempo integral $(14,9 \%)$, sendo de $47,5 \%$ a proporçáo de escolas com alunos em tempo integral. Ainda que se considere que o padrão de distribuição dos alunos por escola é muito variado, a grande diferença entre os percentuais de "escolas" e "alunos" mostra a dispersão da presença do regime de tempo integral, que "pinga" pelas escolas, para um número pequeno de alunos, caracterizando-o como dispositivo de apoio compensatório.

\section{Voluntariado, parcerias e novos espaços na ampliação da jornada escolar}

Do ponto de vista da ação educacional cotidiana, a espinha dorsal do PME são os monitores. As atividades desenvolvidas por eles são de natureza voluntária, nos termos da já citada Lei $n^{\circ} 9.608$, pelas quais recebem ajuda de custo. Há basicamente dois tipos de monitores: estudantes universitários e agentes comunitários detentores de algum saber específico.

Devido à condição precária desse vínculo de trabalho, a rotatividade desses agentes é alta, especialmente nos grandes centros, o que agrava ainda mais as dificuldades de integração das atividades por eles conduzidas com as atividades da escola. Salvo exceçôes, há pouco contato entre eles e os professores. Em locais onde há distribuição de bônus pelo bom desempenho da escola, prática cada vez mais comum nos sistemas públicos de educação, os monitores, não tendo vínculos efetivos, ficam de fora. 
Um outro núcleo importante da proposta do PME se inspira no movimento das cidades educadoras que - com esse ou outros nomes (bairro educador, bairro-escola, escola integrada e outros) - aparece nas experiências de ampliação da jornada escolar. Trata-se de uma compreensão da cidade como lócus educativo, a requerer a presença constante e intensiva dos estudantes nos espaços públicos, bem como a troca e sinergia entre a escola e o seu entorno. É uma proposta inovadora e interessante, fruto de determinadas realidades sociais, urbanas e educacionais. No Brasil, sua justificativa, diferentemente daquela do movimento original europeu, é com frequência uma função da ausência de infraestrutura e espaço nos prédios escolares para a ampliação do tempo escolar, tendo sido chamada de "tecnologia educacional de baixo custo" em folheto de apoio ao PME (CIDADE ESCOLA APRENDIZ, s.d.).

No entanto, a proposta das cidades educadoras é uma estratégia político-educacional de alta complexidade e não uma solução meramente técnica ou emergencial. Ela não prescinde de uma participação comunitária organizada e institucionalizada, algo particularmente difícil nas comunidades brasileiras desfavorecidas, com parcos equipamentos públicos e que são o foco do PME. Daí as dificuldades encontradas para a efetivação, no contexto brasileiro, das políticas inspiradas nas cidades educadoras. (SANTOS, 2010)

As parcerias são outro elemento forte no $\mathrm{PME}$, associadas ou não ao conceito das cidades educadoras. Nas condiçóes dadas, quando se obtêm parcerias com instituiçóes locais visando o uso de seus espaços, a precariedade das instalaçôes e das vias urbanas e a impropriedade em se utilizar templos religiosos - quase sempre as únicas instituiçóes existentes além da própria escola - emperram ou desvirtuam o desenvolvimento desse tipo de alternativa.

Quando se obtêm parcerias bem sucedidas para uso de espaços extraescolares, elas quase sempre se estabelecem com instituiçóes públicas como quartéis, centros esportivos ou bibliotecas. Mais frequentemente se dá a situação contrária na qual o prédio escolar é o único equipamento público disponível, sendo utilizado para outras finalidades de interesse coletivo das comunidades.

Em termos de parceria, o que predomina hoje da área educacional são aquelas com organizações de grande porte, de origem empresarial, com ou sem fins lucrativos, que prestam consultorias aos órgãos de governo (ministérios e secretarias) para a formulação política, elaboração de documentos e materiais de orientação aos professores. No PME destacam-se, entre outras o Cenpec e a Cidade Escola Aprendiz. (SILVA, 2013) Essas entidades atuam também na organização de encontros e avaliaçóes e deixam uma marca político-pedagógica no discurso e na concepçáo de ampliaçáo da jornada escolar, inspirada predominante nas recomendaçôes dos órgãos internacionais para a educação. 
A maior parte da atuação de organizaçóes sociais nas escolas, seja no PME ou em outros projetos, caracteriza-se por não partir da iniciativa das escolas e não ser controlada por elas (RUSSO, 2013), mantendo-se estranha ao corpo escolar e atuando em função de uma "legitimidade" adquirida em instâncias longínquas. Quanto às relaçóes de trabalho, os agentes educacionais ligados às organizaçôes externas que chegam às escolas têm vínculos "empregatícios" precários e uma confusa cadeia de comando.

Com todos esses elementos, o modelo do PME torna-se intrinsecamente contraditório e fica a meio caminho entre uma gestão burocrática centralizada, ao promover a relação direta das instâncias administrativas do Ministério da Educação com as escolas que aderem ao PME (OLIVEIRA, 2014) e uma gestão gerencial, na direção do público não-estatal, com forte participação do chamado terceiro setor. Como resultado, até aqui, a associação desses dois caminhos não trouxe soluçóes para os problemas da precariedade dos meios físicos e da estabilidade docente e nem favoreceu o desenvolvimento de práticas democráticas de gestão da escola.

\section{À guisa de conclusão}

Retomando a pergunta inicial a respeito do papel da ETI na promoção do direito à educação de qualidade, a reposta vem condicionada mas, assim esperamos, mais qualificada.

A resposta é sim desde que a maior duração sirva à realização de um trabalho válido e indispensável para toda e qualquer criança ou adolescente. De acordo com Cury (2008), a partir da Constituiçấo Federal de 1988 a educaçáo é "erigida em bem público", para o que é imprescindível que tenha "algo de comum ou universal". Ainda segundo o autor, a incorporação do direito à diferença, efetivada pela LDB 1996, não exclui o direito à igualdade, pelo contrário, é somente a partir desse último que o primeiro pode existir.

Se todas as crianças precisam de cuidados durante o período de trabalho dos pais, se essa é uma questão para todo o planeta, que vem sendo resolvida de diferentes formas, a depender das culturas específicas e dos recursos disponíveis, recomenda o bom senso não tapar o sol com a peneira. Há um problema colocado. Entretanto, reconhecer o fato de que o tempo integral atende a uma demanda relacionada aos interesses cotidianos da vida prática das famílias, não o enfraquece como demanda educacional propriamente dita, a menos que as soluçóes que se apresentem sejam de curto alcance.

Com todos esses limites, pode-se afirmar que o PME contribuiu para que a ideia e a possibilidade da ETI se tornasse uma questấo efetiva na educação 
brasileira, a ser tratada, aprimorada, repensada. Por se tratar de uma estratégia indutora do governo federal, dirigida aos estados e municípios, inevitavelmente esse caminho será matizado e modificado, por essas instâncias de governo. A depender dos recursos e do avanço das reflexões, a direção poderá ser um modelo de ETI mais consistente e com perspectivas de reprodução a médio prazo. São os municípios e estados que, na prática, irão desenvolver seja uma concepção de escola de tempo integral que se limite a ser mais um dispositivo de atendimento às crianças e adolescentes em condição de vulnerabilidade social ou educacional, seja uma concepção de escola que ofereça uma educação ampliada, multidimensional e democrática, com ou sem o rótulo de "educação Integral".

Vários municípios têm avançado no estabelecimento de regulamentaçôes e práticas próprias. Alguns já as tinham antes mesmo do PME e adotaram o programa adaptando-o ao que já haviam construído. Há municípios e estados que, ao mesmo tempo, gerenciam o PME no conjunto da rede e implantam, aos poucos, unidades escolares de tempo integral, especialmente estruturadas para tal, com todos os alunos permanecendo em turno integral, apoiadas em regulamentação própria. Os municípios de Mesquita (RJ), Resende (RJ), Niterói (RJ), Rio de Janeiro (RJ) e Juiz de Fora (MG) são alguns exemplos de uma coexistência frutífera. Trabalhos acadêmicos recentes demonstram a variedade das soluçôes encontradas por estados e municípios na implantação das ETI, com ou sem a participação do PME. (CASTRO; SPERANDIO, 2013; ARDITO, 2013; COSTA, 2011)

Há que se pensar se a inexistência de projetos pedagógicos específicos nas ETI, articulados a um verdadeiro fortalecimento da instituição escolar e de seus profissionais, para além de uma coleçâo de atividades oferecidas nos moldes aqui expostos, está transformando esse tempo ampliado em tempo para a pacificação e controle dos alunos, com muito pouca repercussão na qualidade educacional.

Entre um caminho que se realiza como política de Estado para a promoção do direito à educação e outro que se acomoda nas franjas da filantropia, seja ela uma filantropia independente ou a expressão do chamado "filantrocapitalismo" (BISHOP; GREEN, 2009) será preciso fazer escolhas e formular propostas coerentes.

\section{Notas}

1. Os macrocampos, em 2014, definidos pelo MEC são: Acompanhamento Pedagógico (obrigatório); Comunicação, Uso de Mídias e Cultura Digital e Tecnológica; Cultura, Artes e Educação Patrimonial; Educaçáo Ambiental, Desenvolvimento Sustentável e Economia Solidária e Criatival Educação Econômica; Educação em Direitos Humanos; Esporte e Lazer; e Promoção da Saúde.

2. Entre outros, o PME adota as publicaçóes "Bairro-Escola passo a passo", elaborada pela Associação Cidade Escola Aprendiz, com apoio UNICEF e MEC, e "Muitos lugares para aprender", realizada pelo Centro de estudos e pesquisa em educação, cultura e ação comunitária (Cenpec), 2003, com apoio da Fundação Itaú Cultural. 


\section{Referências}

ARDITO, L.B.V. A escola de tempo integral e a qualidade da educação pública: relato de uma experiência de educação integral na cidade de São Paulo. In: COELHO, L. M. C. (Org.). Educação integral: história, políticas e práticas, Rio de Janeiro: Rovelle, Faperj, 2013.

BISHOP, M.; GREEN, M. Filantrocapitalismo - Cómo los ricos pueden cambiar el mundo. Espanha: Urano, 2009.

BOURDIEU, P. Futuro de classe e causalidade do provável In: BOURDIEU, P. Escritos de Educação. Petrópolis: Vozes, 1998.

BRASIL. Lei n. 9.608 de 1998. Dispóe sobre o serviço voluntário. Diário Oficial [da] República Federativa do Brasil, Brasília, DF, 19 fev. 1998.

. Lei n. 10.172 de 2001. Aprova o Plano Nacional de Educação (2001-2010). Diário Oficial [da] República Federativa do Brasil, Brasília, DF, 10 jan. 2001.

. Decreto n. 6094 de 2007. Dispóe sobre a implementação do Plano de Metas Compromisso Todos pela Educação. Diário Oficial [da] República Federativa do Brasil, Brasília, DF, 25 abr. 2007a.

. Portaria Normativa Interministerial n. 17, de 24 de abril de 2007. Institui o Programa Mais Educação. Diário Oficial [da] República Federativa do Brasil, Brasília, DF, 2007b Brasília, DF, 2007b.

. Lei n. 12.101 de 2009. Dispóe sobre a certificação das entidades beneficentes de assistência social. Diário Oficial [da] República Federativa do Brasil, DF, 30 nov. 2009.

. Lei n. 13005 de 2014. Aprova o Plano Nacional de Educação (2014-2024). Diário Oficial [da] República Federativa do Brasil, Brasília, DF, 26 jun. 2014.

. Ministério da Educação. Lei n. 11.494 de 2007. Regulamenta o FUNDEB. Diário Oficial [da] República Federativa do Brasil, DF, 21 jun. 2007.

. Ministério da Educação. Sistema integrado de monitoramento, execução e controle. Brasília, DF, 2014. Disponível em http://simec.mec.gov.br/pde/graficopne.php.

- Ministério da Educação. Fundo Nacional de Desenvolvimento da Educação. Resolução n. 14 de 2014. Destina recursos financeiros nos moldes operacionais e regulamentares do PDDE, a escolas públicas municipais, estaduais e do Distrito Federal [...] com o Programa Mais Educação. Diário Oficial [da] República Federativa do Brasil, Brasília, DF, 10 jun. 2014.

. Ministério da Educação. Instituto Nacional de Estudos e Pesquisas Educacionais Anísio Teixeira. Sinopse Estatística da Educação Básica, 2010, 2011, 2012, 2013. Brasília, DF, 2010. Disponível em http://portal.inep.gov.br/basica-censo.

. Ministério da Educação. Instituto Nacional de Estudos e Pesquisas Educacionais Anísio Teixeira. Resumo Técnico do Censo Escolar da Educação Básica 2011. Brasília, DF, 2012. 
BRASIL. Ministério da Educação. Instituto Nacional de Estudos e Pesquisas Educacionais Anísio Teixeira. Resumo Técnico do Censo Escolar da Educação Básica 2012. Brasília, DF, 2013.

. Ministério da Educação. Instituto Nacional de Estudos e Pesquisas Educacionais Anísio Teixeira. Apresentação coletiva censo da educação básica 2013. Brasília, DF. 2014 b. Disponível em http://download.inep.gov.br/educacao_basica/censo_escolar/apresentacao/2014/apresentacao_coletiva_censo_edu_basica_022014.pdf.

BROOKE, N.; SOARES, J. F. (Orgs.). Pesquisa em Eficácia Escolar. Belo Horizonte: Ed. UFMG, 2008.

CABEZUDO, A. Cidade Educadora: uma proposta para os governos locais. In: GADOTTI, M.; PADILHA, P. R.; CABEZUDO, A. (Orgs.). Cidade Educadora. São Paulo: Cortez, 2004.

CASTRO, J. M. P.; SPERANDIO, A. Programa estadual Mais Tempo na Escola. In: COELHO, L. M. C. (Org.) Educação integral: história, políticas e práticas. Rio de Janeiro: Rovelle, Faperj, 2013.

CAVALIERE, A. M. Notas sobre o conceito de educação integral. In: COELHO, L. M. (Org.). Educação integral em tempo integral: estudos e experiências em processo. Petrópolis: Faperj, 2009.

CIDADE ESCOLA APRENDIZ. Bairro-escola passo a passo. Associação cidade escola aprendiz. MEC, Unicef, Prefeituras de Belo Horizonte e Nova Iguaçu, s.d. 4p.

COMPÈRE, M. M. Histoire du temps scolaire en Europe. Paris: Éditions Econômica, INRP, 1997.

COSTA, V. L. Mais tempo nalde escola: estudo sobre as experiências de ampliação da jornada escolar no município de Russas (CE). 161p. 2011. Dissertação (Mestrado em Educação) Escola de Educação - Universidade Federal do Estado do Rio de Janeiro, 2011.

CURY, C. R. J. A educação básica como direito. Cadernos de Pesquisa, São Paulo, v. 38, n. 134, p. 293-303, 2008.

MOTA, C. N. O programa de educação em tempo integral da prefeitura municipal de Vitória (ES). 196p. 2013. Dissertaçáo (Mestrado em Educação) - Centro de Educação - Universidade Federal do Espírito Santo. 2013.

OLIVEIRA, R.C. Programas PDE escola e Mais Educação: descentralização e gestão do Ensino. 330p. 2014. Tese (Doutorado em Educação) - Faculdade de Educação - Universidade Federal de Juiz de Fora, 2014.

PEREYRA, M.A. A jornada e os tempos escolares numa nova época. In: MAURÍCIO, L. V. (Org.). Tempos e espaços escolares. Rio de Janeiro: Ponteio, Faperj, 2014.

RUSSO, K. Parceria entre ONGs e escolas públicas: alguns dados para reflexão. Cadernos de Pesquisa, São Paulo, v. 43, n. 149, p. 614-641, 2013.

SAVIANI, D. O Plano de desenvolvimento da educação: análise do projeto do MEC. Educação \& Sociedade, Campinas, vol. 28, n. 100 - Especial, p. 1231-1255, out. 2007 
SANTOS, T. L. A. Inovaçôes e desafios do programa Bairro escola de Nova Iguaçu/RJ. 159p. 2010. Dissertação (Mestrado em Educação) - Faculdade de Educação - Universidade Federal do Rio de Janeiro, 2010.

SILVA, B. A. R. Interesses, dilemas e a implementação do programa Mais Educação no município de Maricá (RJ). 274 p. 2013. Tese (Doutorado em Educação) - Faculdade de Educação - Universidade Federal do Rio de Janeiro, 2013.

SOUZA, A. S. Mais Educação numa Escola do Amanhãa: educação integral ou assistencialismo? 2012. Monografia (Especialização em Educação), Faculdade de Educação - Universidade Federal do Rio de Janeiro, Rio de Janeiro, 2012.

Recebido em 24 de novembro de 2014. Aprovado em 27 de fevereiro de 2015. 